\title{
Procurando superar a modelização de um modo de envelhecer
}

Edmundo de Drummond Alves Junior

\begin{abstract}
Resumo: Fundamentada em uma pesquisa empírica realizada junto a grupos de idosos que praticavam ginástica nas cidades Rio de Janeiro e Rennes (Franca), esse texto objetiva discutir o lazer e o envelhecimento dentro de uma sociedade que privilegia o jovem, o poderoso e o belo. Nesse sentido destaca a atuação do animador cultural como um profissional cuja intervenção pode atuar no educar pelo e para o lazer a partir de abordagem mais crítica sobre envelhecimento e a sociedade de forma a evitar o que denomino de "pastoral do envelhecimento ativo".

Palavras-chave: Envelhecimento, Lazer, Animador, Cultural
\end{abstract}

Ao fazer uma história da velhice, Jean-Pierre Bois (1994:4) argumentou que, não importando o período em que ela foi abordada, o discurso que se fez passará sempre por uma discussão de

... temas em oposição mas sem dúvida complementares - sabedoria e loucura felicidade e tristeza, beleza e feiúra, virtudes e corrupções de idade e das pessoas idosas - que exprimem duas aspirações, a tentação de uma vida longa e a recusa das fraquezas clássicas da idade.

O século XX passou a ser considerado um período bastante importante no tocante ao interesse social pelas coisas da velhice, momento em que uma "nova velhice" passou a ser delineada, surgindo as associações gerontológicas e geriátricas para dar as diretrizes do envelhecer saudavelmente (Haddad, 1986). Época da "hiperatividade contemporânea", de contato com uma "nova arte de envelhecer" (Myra y Lopes, 1966), um resgate da época dos iluministas do século XVIII que passaram a apresentar uma imagem positiva de uma nova maneira de envelhecer.

O envelhecimento e a velhice tornaram-se no decorrer do século passado um problema social com importantes repercussões que avançarão neste século XXI: seja na formulação de políticas sociais,

* Doutor em Educação Física, professor da Universidade Federal Fluminense.

Movimento, Porto Alegre, v. 10, n. 2, p.57-71, maio/agosto de 2004 
haja visto que já se possui no país uma lei específica para tratar dos direitos dos idosos (Brasil, 1994) e um Estatuto do Idoso promulgado recentemente (Brasil, 2003); nas reformulações das políticas previdenciárias e na forma de cálculo dos benefícios dos segurados, tanto do setor público como privado, que levaram em consideração os fatores que afetam a transição demográfica que passa o país (Brasil, 2001, US Census Bureau, 2003). Apontamos também o interesse crescente: do meio acadêmico em investigar o envelhecimento e a velhice a partir das mais variadas óticas, desde os aspectos mais sociais e humanos, aos de cunho mais biológico. É fato que os mais de 15 milhões de brasileiros com mais de sessenta anos, enquanto eleitores potenciais que são, não serão mais desprezados nos discursos dos candidatos a cargos eletivos. Este quantitativo que hoje representa quase $9 \%$ da população, daqui a vinte e um anos representará $16 \%$ do total dos brasileiros não passam mais desapercebidos de um excelente nicho de consumidores, cada vez mais integrados num mercado que se apresenta atento as especificidades desse grupo não parará de crescer (US Census Bureau, 2003).

Diante desse quadro atual e prospectivo, passaram a ser preocupações: questões relacionadas à promoção da saúde e do bem estar dos idosos; como integrar as diversas gerações, buscando cada vez mais diminuir os preconceitos com relação a idade cronológica e a vida de aposentado. Uma vez que a forma asilar passou a ser o último recurso, tanto o lazer e a educação para idosos e aposentados, passaram a fazer parte das mais diversas propostas associativas, tornando-se alternativas para manter inseridos socialmente os que envelhecem. A prática de atividades físicas e dos esportes não é mais algo estranho aos que envelhecem e motivos dos mais diversos os levam a se engajar. Temos considerado que grande parte dos praticantes buscam atividades que lhes proporcionem prazer e possibilitem a interação com os outros, estamos chamando isso de uma forma de utilização do tempo disponível com atividades de lazer (Alves Junior, 2001; 2000; 1999). Entretanto, sem que haja por parte dos animadores das atividades uma reflexão mais crítica da sociedade que envelhece, consideramos bastante inócua as intervenções pontuais, que muitas vezes infantilizam e escolarizam os conteúdos utilizados fato observado em muitos projetos de intervenção (Alves Junior, 1997).

Encontrarmos com certa regularidade projetos voltados aos idosos brasileiros que como estratégia de sensibilização dos seus participantes enaltecem de forma exacerbada a etapa da vida que

Movimento, Porto Alegre, v. 10, n. 2, p.57-71, maio/agosto de 2004 
ronda a aposentadoria como um período em que tudo seria permitido e extensivo a todos, independente das suas origens sociais. A glamourização do envelhecimento saudável, engajado e ativo, a nosso entender acaba por camuflar as injustiças que são cometidas a uma significativa parcela da população brasileira. Nesta forma de raciocínio, acaba-se por condenar ao declínio aqueles que não optarem por uma vida de engajamento associativo, incluindo as atividades físicas e de lazer. Foi pensando nas contradições de uma sociedade que privilegia o jovem, o poderoso e o considerado estéticamente dentro dos padrões contemporâneos que buscamos investigar a formação e o desenvolvimento do que chamamos de uma "pastoral do envelhecimento ativo" (Alves Junior, 2004).

Falar hoje no envelhecimento de uma população não se restringe mais ao seleto grupo que ainda pode usufruir um modo de vida que encara o envelhecimento como uma fase da vida só de lazeres e de prazeres, muitas vezes não consumados no tempo de vida ativa. Não são poucos aqueles que atingem cada vez mais as idades bem avançadas e cujo estado de dependência é bastante lamentável. Consideramos que tanto estes como os "idosos hipodotados", identificados mais facilmente no Brasil (Magalhães, 1989), não se enquadram na ideologia da terceira idade ativa, que habilmente procura camuflar a existência de sua realidade. Vários fatores têm influído para a transformação do envelhecimento, enquanto processo que só importava ao indivíduo, a destino não mais de poucos privilegiados, assunto de responsabilidade social.

\section{Lazer uma necessidade social independente da idade cronológica}

Ao mesmo tempo em que vimos avançar o envelhecimento da população, outros fatos também estavam ocorrendo: mais tempo disponível para o indivíduo; maior interesse por atividades consideradas de lazer; multiplicação dos esportes modernos. Esses fenômenos sociais têm sido caracterizados como conseqüência da urbanização dos grandes centros, e passaram a ocorrer tanto em decorrência do processo de industrialização como da artificialização do tempo do trabalho (Melo, Alves Junior, 2003). Nossa intenção tem sido de apresentar reflexões que não podem passar desapercebidas daqueles que atuam com idosos, principalmente àqueles que atuam no campo do lazer, incluindo nele os que se utilizam da prática das atividades físicas esportivas.

Movimento, Porto Alegre, v. 10, n. 2, p.57-71, maio/agosto de 2004 
Estamos considerando a existência de um importante campo de intervenção e estamos defendendo a adoção do nome 'animador cultural', diferentemente da tradição européia de chamar de animação sociocultural (Trilla, 1998) para caracterizar aqueles que podem vir a intervir no campo da educação e do lazer para idosos. Reconhecemos que no Brasil ainda são poucas as iniciativas de se discutir a atuação desse animador num contexto tanto específico como global. Neste último registramos a recente iniciativa apresentada no IV Seminário Lazer em Debate, que ocorreu na cidade do Rio de Janeiro no ano de 2004. Em muitas ocasiões a percepção do que estamos denominando como animador, fica marcada como sendo algo de menor importância, ainda com pouco trânsito no campo acadêmico.

Temos considerado como fundamental a formação daqueles que vão atuar com pessoas idosas ou aposentadas, no entanto nem sempre estes profissionais estão atentos a determinadas especificidades de um grupo que nada têm de homogêneo, e que tem demandas que os diferencia substancialmente de crianças ou mesmo de adultos jovens.

Os momentos dolazer não podem ser compreendidos como instantes de alienação, desconectados da realidade social, tampouco como espaços de fuga, o que não significa que devamos desconsiderar o prazer, uma das características fundamentais de sua definição (MELO \& ALVES JUNIOR, 2003, p.51)

\section{Ao negar a velhice acaba-se comprometendo uma intervenção consciente}

Não importa o período analisado na história da humanidade, seja nas culturas mais antigas, seja nos países mais jovens, os significados atribuídos ao 'ser velho' e ao envelhecimento foram sempre marcados por profundas contradições. Uma pessoa velha pode ser considerada como alguém que merece e impõe respeito, ou um indivíduo altamente desprezível. Na atualidade, testemunhamos ser bastante comum recorrer-se ao uso da palavra 'velho' para uso mais pejorativo e depreciativo do que lisonjeiro.

No momento em que a velhice é apresentada como um período da vida ao qual se associam mais desvantagens do que vantagens, constata-se com freqüência a busca de distanciamento desse processo. É fato que existe grande controvérsia sobre qual seria o momento ideal para marcar o início dessa tal velhice. O mais

Movimento, Porto Alegre, v. 10, n. 2, p.57-71, maio/agosto de 2004 
freqüente é o uso da idade cronológica para se dizer quando alguém é velho, ou então se recorre a determinados comportamentos ou a um modo específico de envelhecer. Fica claro que não é muito simples nem unânime qualquer tentativa de caracterização desse momento. A falta de consenso é presente, seja no uso de critérios cronológicos, seja na importância que se dá aos sinais externos, apresentados por meio das mudanças corpóreas ou orgânicas, que acabam refletindo na variedade de conselhos que são dados em cada época para se enfrentar a velhice.

Podemos verificar numa breve análise dos ensinamentos propostos em algumas publicações de mais de cinqüenta anos a ambigüidade a que nos referimos. Com o significativo título $A$ vida começa aos quarenta anos, Pitkin (1942) apresenta um modo de vida que deveria ser assumido para se ter uma boa velhice, o autor uma faixa etária para caracterizar o início da velhice que seria impensável nos dias de hoje. Outra curiosidade pode ser encontrada nos ensinamentos propostos pelo Dr. Peter Steincrohn (1950), que publicou um livro com o título O repouso começa aos quarenta. Reforçando a idade de quarenta anos como simbólica para o início da velhice, o livro procurava ensinar ao 'quarentão' de que forma ele poderia ter uma velhice mais saudável. Basicamente a recomendação principal é a de que não é preciso fazer ginástica, pois aqueles que se dedicam a ela gastam as poucas reservas energéticas que ainda sobrariam para enfrentar os últimos anos de vida.

Assim como a juventude, podemos considerar a velhice mais uma categoria criada culturalmente. Segundo Pierre Bourdieu (1980:145), “a idade é uma variável biológica, socialmente manipulada", por esse motivo plena de ambigüidades que não serve como único parâmetro para dizer quando alguém é velho. Não podemos ignorar, entre outras, as variáveis derivadas: das influências do meio ambiente; das condições de trabalho; da classe social e do modo de vida. Na verdade, os cortes cronológicos só contribuem para aumentar as barreiras entre gerações (AttiasDonfut, 1988). Defendemos como sendo de fundamental importância a preparação dos que vão intervir com idosos e aposentados percebendo o envelhecimento como um processo normal e inexorável, tanto multidiferencial como multidimencional. Consideramos como equivocada a compreensão da velhice como sendo um período da vida unicamente associado a desvantagens.

Movimento, Porto Alegre, v. 10, n. 2, p.57-71, maio/agosto de 2004 
Remi Lenoir (1998:68) adverte que as faixas etárias enquanto classificações arbitrárias estão sujeitas a manipulações, deixando claro que

o que está em questãoéa definição dos poderes associados aos diferentes momentos do ciclo da vida, sendo que a amplitude e o fundamento do poder variam segundo a natureza das implicaçôes - peculiares a cada faixa etária ou a cada fração da faixa-da luta entre as gerações.

Sendo assim, alguns buscam compreender o inexorável processo do envelhecimento enquanto um processo gradual, sendo importante que os aspectos deletérios do envelhecimento sejam enfrentados e não negados ou camuflados.

\section{A pastoral impondo modelos sociais de envelhecimento: seja ativo para não ser um velho dependente}

Indesejável durante o século XX, a velhice acabou se tornando um problema social, principalmente nas sociedades que exacerbaram na valorização das coisas mais afetas à jovialidade. Como conseqüência da perspectiva 'anti-envelhecimento' das últimas décadas, desprezam-se, de forma direta ou velada, os velhos e a velhice. Se por um lado aumenta-se a longevidade, a expectativa de vida e a proporção de pessoas aposentadas frente aos mais jovens, paradoxalmente entre os novos aposentados poucos querem se assumir como velhos ou próximo da velhice. Como alternativa, criam-se novas denominações e impõem-se modos de vida para eles, que associam essa fase da vida a um período em que tudo é aparentemente permitido e possível de ser feito. É inegável que nunca se falou tanto nessa nova idade, a 'terceira idade', e no envelhecimento bem-sucedido daqueles que optarem por seguir determinados conselhos.

O que estaria por trás dessa pretensa redenção social para com aqueles que envelhecem? Será que a sociedade contemporânea está passando a ter mais preocupação, respeito e solidariedade, ou, ao contrário, estaria cada vez mais individualista, tentando encontrar meios de se afastar e negar um modelo de velhice que associa a pessoa à idéia de inutilidade e de peso para a sociedade? Em geral os próprios idosos não se sentem à vontade para falar da sua velhice, os exemplos são sempre a partir dos outros. Na procura de se redefinir o significado da velhice, expressões como 'feliz idade',

Movimento, Porto Alegre, v. 10, n. 2, p.57-71, maio/agosto de 2004 
'melhor idade', 'boa idade' e 'terceira idade' procuram transparecer que existe para os aposentados uma nova fase da vida, vista como um período alentador.

Não é difícil constatar que essas referências pecam pela ingenuidade aliada à tentativa de homogeneização de pessoas que só têm em comum o fato de terem nascidos na mesma época. Não se pode negar que a mídia em geral vem exercendo um papel de grande divulgador dessa perspectiva de envelhecimento em que aos idosos pertencentes a essa 'idade dourada' tudo seria permitido e possível de ser experimentado. Como modelo, a velhice passou a ser substituída pela terceira idade, ativa e engajada, que tem sido a fórmula de maior sucesso, não por acaso fazendo parte das políticas sociais destinadas aos idosos.

A parir da gerontologia e geriatria, que são duas ciências aplicadas, pode-se perceber melhor que parte significativa dos idosos passou a ser confrontada a uma nova maneira de envelhecer. No caso dos novos aposentados, chegam mesmo a ser vistos como um novo poder. A nova moral do envelhecimento ativo busca de todas as maneiras subterfúgios para esconder a velhice ou mesmo ignorá-la. Ser velho passa a ser algo presente nos que são dependentes, inativos, isolados socialmente que estão na quarta idade.

A maneira como uma sociedade envelhece vem sendo apontada como capaz de influenciar mutuamente a política, a economia e as relações entre as gerações. É um fato que não se deu de forma semelhante em nenhuma outra época, sendo surpreendente o que ocorre em diversos países nestes últimos anos. Se os anos sessenta ficaram caracterizados pela revolução em diversos sentidos empreendida pelos jovens, quarenta anos mais tarde estamos entrando numa época em que, pelo menos em aparência, busca-se privilegiar uma nova geração de pessoas que envelhecem.

A década dos noventa talvez signifique a constatação de que um novo poder, o dos velhos, está marcando a sua presença no mundo. As universidades para a terceira idade florescem uma ao lado da outra, mesmo no interior de instituições que durante séculos foram pensadas como lugar da juventude, do novo, da potência [...]. Saúde, bem-estar, qualidade de vida elongevidade tornam-se valores a serem perseguidos, assim como campo de investimentos econômicos, intelectuais e simbólicos (Lovisolo, 1997, p.10).

Estudar a velhice e o envelhecimento nos dias atuais é se debruçar sobre questões as mais diversas, que entre outros fatores

Movimento, Porto Alegre, v. 10, n. 2, p.57-71, maio/agosto de 2004 
envolvem: os direitos sociais, como acesso à saúde e ao lazer; a aposentadoria e o sistema de idades no qual estão fundamentadas as gerações dos atuais idosos; o modo de vida, bem como as atividades assumidas no período que ronda a aposentadoria.

Muitos estigmas do significado do 'ser velho' têm origem na valorização que é dada ao trabalho e ao engajamento produtivo, que no curso da vida acabam ficando cada vez mais presentes. Se em algumas épocas aos aposentados quase sempre era recomendado descanso, recolhimento e inatividade, depois da metade do século XX outros valores ganharam importância. Fenômenos como o associativismo e a participação em atividades socialmente reconhecidas, como o voluntariado, passam a ser incorporados, resultado do novo modelo, que acaba caracterizando o que é bom ou mau para o envelhecimento. Em nosso entender isso está bem de acordo com o que tem sido sustentado pelos seguidores de algumas teorias psicossociais sobre o envelhecimento e a velhice bem-sucedida.

Independente do que é feito, se a atividade tem predominância física ou intelectual, tendo mais ou menos gasto energético, a proposta ativista encontrou no ambiente associativo o espaço ideal para a prática dos seus mais caros princípios. As associações de idosos, como clubes ou universidades, surgiram como um antídoto, uma verdadeira panacéia contra a velhice (Alves Junior, 2004).

Foi a partir dos anos sessenta que na Europa, em especial na França, ao mesmo tempo em que se criavam grupos que visavam à preparação para a aposentadoria, também surgiam as associações para idosos já aposentados. Ambos passaram a incluir a idéia de um envelhecimento ativo e engajado em associações nos períodos pré e pós-aposentadoria. Pode-se perceber que inicialmente havia um forte viés para a ocupação do tempo, visando a inclusão e (re) inserção social, sem muita preocupação com a qualidade do que viria a ser apresentados, mas posteriormente, com a chegada de novos aposentados com forte 'capital cultural', incorporaram-se os princípios da educação permanente nas propostas associativas em que 'animadores culturais' sobre as mais variadas denominações, passaram cada vez mais a atuar, havendo uma demanda cada vez mais crescente na qualificação destes quadros.

Acrescentaríamos o fato de que os novos aposentados passaram a ter uma maior esperança de vida, lhes restando uma considerável expectativa de viver a vida com saúde, passou a ser viável viver a aposentadoria de forma totalmente diferente. O que se passou a

Movimento, Porto Alegre, v. 10, n. 2, p.57-71, maio/agosto de 2004 
dizer é que "o indivíduo não deveria mais aceitar passivamente seu envelhecimento, mas prolongar a vida, pelas atividades físicas, intelectuais e voluntárias, o maior tempo possível" (Bourdelais, 1993, p.373). Chega-se mesmo a culpabilizar aqueles que venham a apresentar deterioração física, sendo a dependência e a decrepitude resultados de uma conduta desviante do indivíduo. Sendo assim, inatividade corresponderia a velhice, opondo-se às vantagens do envelhecimento 'terceira idade'.

Idosos e aposentados foram transformados nas últimas décadas do século XX em categorias boas de se investir, não sendo poucos os que se viram atraídos pelos apelos da mídia que lhes acenava com um novo imaginário do que poderia ser seu envelhecimento num novo tempo mais independente

das sanções, das repressões, dos desejos, das necessidades antigamente reprimidas pela ideologia de trabalho (política e religiosa). A associação desses valores sócioculturais emergentes (saúde, lazer, sociabilidade, divertimento) conferem a via de acesso a algumas mudanças de valores e práticas que os idosos estabelecem no emprego do seu tempo livre - para crescimento pessoal e sua integração social - de forma mais expontânea e voluntária. Tal atitude dos idosos, sem dúvida, tem contribuído para a imagem de pessoas independentes e ativas que lhes é habitualmente associada (Vendruscolo, Lovisolo, 1997, p.40).

Ao alterar-se a percepção da velhice, "passando da deterioração à conservação" (Bourdelais, 1983, p.364), o discurso das doenças, da conotação negativa do envelhecer acabou sendo substituído por uma nova higiene de vida., a do idoso ativo que faz qualquer coisa independente de maior reflexão sobre o que é feito e o por que lhe é proposto determinadas atividades.

Nas pesquisas empreendidas por Georges Vigarello (1996) acerca dos hábitos de limpeza dos europeus em épocas passadas, ficou caracterizada a existência de uma 'pastoral da saúde'. Segundo suas análises, pode-se verificar como era passada uma nova moral higienista, que veio sendo difundida por meio de estratégias pedagógicas. ${ }^{1}$ Será que de forma semelhante, no caso do bom envelhecimento e das atividades em geral, especificamente as físicas, não estaríamos diante de influências moralizantes e, usando

1 As recomendações dos manuais de higiene endereçados às famílias, bem como aqueles voltados para a higiene popular davam sugestões, conselhos aqueles voltados para a higiene popular, davam sugestoes, conselhos e "estabeleciam preceitos. O tratado de higiene destinado ao povo é bastante "militante". A sujeira passou a ser considerada resultado da preguiça, e incluíase tanto nos manuais dos alunos como nos dos professores certas "normas que foram criadas para os indigentes" (Vigarello, 1996:215).

Movimento, Porto Alegre, v. 10, n. 2, p.57-71, maio/agosto de 2004 
as palavras daquele autor, diante da imposição de uma verdadeira 'catequese'? A higiene, no caso do estudo por ele empreendido, só "fez confirmar seu status de saber oficial" (Vigarello, 1996, p.215), que veio a ser didatizado, sem no entanto vir a ser confirmado, já que seria muito pouco provável que algumas recomendações prescritas nos textos estudados pudessem ser colocadas em prática. Tal qual essa linha de raciocínio, apresentamos a hipótese de estarmos diante de uma nova pastoral, a 'pastoral do envelhecimento ativo' (Alves Junior, 2004).

\section{Propondo uma intervenção mais reflexiva}

No momento em que ocorre a diminuição do tempo destinado ao trabalho, não existindo grandes pressões, seja de ordem financeira ou de saúde, a família, a religião e o lazer passam a ser as principais ocupações no tempo social das pessoas. Um dos componentes, e provavelmente um dos mais importante relacionado ao que estamos vendo como novo modo de envelhecer, é a possibilidade de se engajar nos diversos projetos associativos. $\mathrm{O}$ fato de aderir a uma associação e praticar as atividades que nela são propostas acaba dando ao idoso uma possibilidade de se sentir mais útil e de permanecer inserido na sociedade, afirmam os que defendem esse modelo ativo e socialmente engajado do bom envelhecer. Nossa crítica neste trabalho é a um modelo de envelhecimento impositivo que não dá qualquer outra escolha ao indivíduo, para alterar este estado atual nossa proposta passa por uma nova forma de perceber o papel dos que vão intervir.

Mesmo que ainda seja bastante reduzido o número de cursos de formação que incluem a temática específica do lazer e as atividades para idosos como disciplina curricular, não impede que seja significativo o número de profissionais, que se apresentem para trabalhar com eles, mesmo sem ter tido qualquer tipo de preparação para atender as especificidades do grupo em questão.

Cada vez mais será crescente o número de oportunidades profissionais para se atuar com os idosos e aposentados interessados em praticar atividades físicas esportivas como lazer. Consideramos como fundamental a atenção à diversidade de públicos, mesmo que eles sejam muito próximos quando se observa a data de nascimento. A melhor compreensão desses públicos certamente contribuirá para a melhor adequação das práticas escolhidas e dos conteúdos utilizados. Identificamos inicialmente, que entre os praticantes, das atividades físicas esportivas, existe um grupo que

Movimento, Porto Alegre, v. 10, n. 2, p.57-71, maio/agosto de 2004 
já vem praticando há algum tempo, muito antes da entrada na aposentadoria. Em geral estes não aceitam qualquer coisa que lhes é proposta, são mais exigentes e talvez por esse motivo fazem suas atividades de maneira informal. No mesmo caso de praticantes experientes, encontram-se os que se investem nos torneios 'masters', em práticas competitivas, que podem também buscar outras finalidades: seja na forma de lazer, estando no meio dos outros, fazendo turismo em viagens que são propostas; ou ainda sentindo-se importantes, fortalecendo sua auto estima pelo fato de estarem praticando atividades socialmente consideradas.

O exemplo dos competidores masters de natação serve para percebemos como os idosos e aposentados podem participar de situações que até pouco tempo eram exclusivas de pessoas jovens. Seus participantes foram analisados por Santiago e Lovisolo ( 1997: 86) sendo uma boa demonstração da resistência ao envelhecimento que acaba estando presente também na maioria dos idosos e aposentados que praticam atividades físicas e esportivas.

Imaginamos que resistir à entropia da velhice signifique montar estratégias que permitam reduzir o rítimo da desorganização, que signifique adotar um regime ou um estilo de vida que reduza os efeitos visíveis e sensíveis do processo de desestruturação, mantendo a vitalidade e autonomia. No plano do corpo, mantendo padrões circulatórios, digestivos, de flexibilidade, resistência e força, que criem a imagem de um funcionamento fisiológico mais novo que o cronológico. No plano social, criandonovos pertencimentos e relacionamentos que mantenham em bom funcionamento a sociabilidade, o prestígio, oreconhecimento e a circulação social.

Fica clara a existência de um outro grupo distinto, que é constituído de idosos e aposentados que com certa regularidade só praticaram atividades físicas em determinado período da vida, muitas vezes de maneira obrigatória, como nas escolas ou nas forças armadas, onde muitas vezes ficou ausente o componente lazer. O abandono após esses períodos acaba sendo justificado pela falta de interesse ou por diversas causas, mas a mais comum é a falta de tempo disponível, já que se privilegiou a dedicação à vida familiar e profissional, ou a outros interesses pessoais. Entre esses idosos, o retorno à atividade pode ser devido a uma recomendação terapêutica específica, como uma opção de viver o envelhecimento de forma diferente, sendo o fator lazer e sociabilidade fundamentais. Finalmente encontramos um terceiro grupo que em muito se assemelha ao anterior, sendo ambos os mais representativos entre aqueles que podem ser observados nos mais diversos grupos que hoje estão nos grupos que propõe atividades

Movimento, Porto Alegre, v. 10, n. 2, p.57-71, maio/agosto de 2004 
das mais diversas. Sua constituição é de pessoas que nunca praticaram regularmente alguma atividade física, e que só após a entrada nas associações de idosos e aposentados passaram a se engajar em programas específicos de atividades físicas, sendo o componente lazer e estar no meio de semelhantes de grande importância.

Levando em consideração que essas atividades podem se desenvolver segundo uma lógica educativa voltada à animação tanto para a saúde, como cultural e social, nosso empreendimento vêm sendo de pensar como deve ser a preparação daqueles que vão intervir com grupos de idosos e aposentados. Apontamos para a chegada de novas gerações de aposentados e idosos, cada vez mais exigentes com relação a qualidade do que lhes é proposto. Para atender as novas demandas e melhorar as intervenções do que atualmente é realizado, consideramos como sendo fundamental pontuar as intervenções a partir de uma abordagem mais crítica sobre envelhecimento e a sociedade, acreditando no sucesso de propostas que levem em conta concepções que possam ser pautadas no educar pelo e para o lazer.

Oprofissional delazer faz um verdadeiro trabalho de mediação, tentandonegociar com seu público alvo a composição de seu programa de intervenção, o que significa sempre compreender as pessoas como partes ativas no processo (Melo \& Alves Junior, 2003, p.53).

Apontamos como possibilidade de intervenção do animador três diferentes perspectivas, passando pelas que visam a manutenção da ordem social, uma outra mais reflexiva, entendendo como necessárias as reformas dessa ordem, enquanto que numa terceira opção se buscaria transformar a estrutura. O primeiro caso seria o 'paradigma tecnológico', onde "a animação é encarada como uma engenharia cultural" (p. 61). Seria o animador o responsável pela interpretação da realidade, apresentando as propostas sem dar muito espaço ao desenvolvimento das potencialidades dos idosos. A segunda característica é chamada de 'paradigma interpretativo', que embora seja um avanço com relação ao anterior, pois incita os participantes a outras reflexões, construídas a partir de experiências individuais. Mesmo que se busque uma ação relacional e criadora esta proposta foi considerada como ingênua "ao acreditar que basta convidar, ainda mais quando a ordem social conclama exatamente ao contrário: à inatividade e ao consumo fácil (p. 62). Já no último paradigma, denominado como 'dialético'. A postura deixa de ser 
vertical como postulava o primeiro paradigma, ou mesmo horizontal como no segundo, para vir a ser diagonal. Nela o animador

...tenta gerar uma reflexão construída e problematizada. Sua preocupação é organizar uma ação comunitária, que se não significa agredir frontalmente as individualidades, significa educar os indivíduos para o entendimento de que a construção de uma coletividade significa negociações, concessões, mediações. A partir daí espera-se gerar uma ação transformadora e emancipadora (p. 63).

De acordo com este último paradigma estaríamos nos contrapondo a uma intervenção que vem se apresentando enquanto hegemônica, que muitas vezes percebe o envelhecimento como um grande gerador de negócios que envolve muito dinheiro, sendo necessário manter os idosos independentes e ativos para serem consumidores o maior tempo possível Uma vez que durante muitos anos "o conhecimento do envelhecimento e da velhice era dominado por mitos, estereótipos, preconceitos, ignorância e medos pessoais com a velhice" (Crandall, 1980, p.4), foi necessário incorporá-la primeiro como uma fase importante da vida e depois considerá-la enquanto um fato social.

Trying to overcome the modelization of a way of
aging
Abstract: Based on a empiric research made with
elderly groups in the cities of Rio de Janeiro and
Rennes (France) this texts seeks to discuss leisure and
aging in a society that privileges the young, the
powerful and the beautiful. In this way it brings out
the role of the cultural animator as a professional
whose intervention can act in the education for and
to leisure from a more critical approach about aging
and society, in a way to avoid what I call "pastoral of
active aging".
Keywords: Aging, Leisure, Cultural, Animator.

Keywords: Aging, Leisure, Cultural, Animator. 


\begin{abstract}
Procurando superar a modelización de un modo de envejecer

Resumen: Fundamentada en una investigación empírica realizada junto a grupos de ancianos que hacian gimnastica en las cuidades de Rio de Janeiro y Rennes (Francia), este texto objetiva discutir el ócio y el envejecimiento dentro de una sociedad que privilegia el joven, el poderoso y el bello. En ese sentido destaca la actuación del animador cultural como un profesional cuya intervención puede actuar en el educar por el y para el ócio a partir de la abordaje mas critica sobre envejecimiento y la sociedad de forma a evitar o que denomino de "pastoral del envejecimiento activo".

Palabras-Chave: Envejecimiento, Ócio, Animador Cultural.
\end{abstract}

\title{
Referências
}

ALVES JUNIOR Edmundo de Drummond, A pastoral do envelhecimento ativo, tese de doutorado, Programa de pós graduação da Universidade Gama Filho, 2004.

Construindo um programa de prevenção de quedas que seja capaz de influir na vida ativa de pessoas com necessidades especiais: preparando-se para um envelhecimento saudável, In: Congresso Brasileiro de Ciências do Esporte, 2001, Anais, Caxambu: CBCE, 2001, CD Rom.

Da Educação Gerontológica à Educação Física Gerontológica: Em busca de uma educação física mais apropriada para idosos, In: PAZ S F (Org), Envelhecer com Cidadania: quem sabe um dia? Rio de Janeiro: ANG, 2000, p. 107: 120.

Objetivando construir uma metodologia mais adequada para prática pedagógica das atividades físicas dos idosos, Arquivos de Geriatria e Gerontologia, 3 (2), p. 57-61, 1999.

Por uma educaçao fisica de qualidade para os idosos, In: Congresso

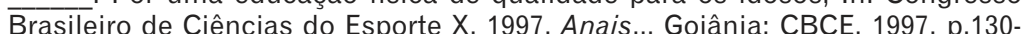
1356.

BOIS Jean-Pierre, Histoire de la vieillesse, Paris: PUF, 1994.

BOURDELAIS Patrice. Le nouvel âge de la vieillesse, Paris: Odile Jacob, 1993. BOURDIEU Pierre, Questions de Sociologie. Paris: Ed. du Minuit, 1980.

BRASIL, Instituto Brasileiro de Geografia e Estatística (IBGE), Dados preliminares do Censo 2000, Rio de Janeiro: IBGE, 2001.

Direitos da terceira idade, lei 8842, RJ: Auriverde, 1996.

Estatuto do Idoso, Lei 10741, Brasilia: DF, 2003

CRANDHALL R C, Gerontology, A behavioral science approach, New York: Newbery, 1980.

Movimento, Porto Alegre, v. 10, n. 2, p.57-71, maio/agosto de 2004 
DOUARD Olivier Les cadres de l'animation à travers leurs écrits professionels. Introduction de l'ouvrage. In: DOUARD Olivier (dir) Dire son métier. Paris, L'Harmatthan, 2003, p. 11-21.

HADDAD Eneida Gonçalves de Macedo, A Ideologia Da Velhice,. Rio de Janeiro: Cortez, 1986.

LENOIR Remi, Objeto sociológico e problema social, In: CHAMPAGNE $\mathrm{P}$ et al, Iniciação à prática sociológica, Petrópolis Vozes, 1998, p. 59-106.

LOVISOLO Hugo, Problematizando a questão da terceira idade no contexto atual da sociedade, Motus Corporis, v. 4, n. 2, nov, p: 9- 13, 1997.

MAGALHÃES, Dirceu Nogueira, $A$ invenção social da velhice, Rio de Janeiro: Papagaio,1989.

MELO Victor Andrade de, ALVES JUNIOR Edmundo de Drummond, Introdução ao Lazer, São Paulo: Manole, 2003.

MYRA y LOPES E, A arte de envelhecer, Rio de Janeiro: Civilização Brasileira, 1966.

PIKTIN W B, Vida começa aos quarenta anos, Porto Alegre: Livraria do Globo, 1942

SANTIAGO Leonéia Vitória, LovISOLo Hugo, Master de natação-competição, aprimoramento e expressão, Motus Corporis, v. 4, n. 2, nov, p: 84-101, 1997.

STEINCROHN Peter, O repouso começa aos quarenta, Rio de Janeiro: José Olímpio, 1950.

TRILLA Jaune, Animacion sociocultural, Barcelona: Ariel, 1998.

US CENSUS BUREAU, Report WP/03, World population profile: 2003, US Gouvernemment Printing Office: Washington DC, 2003. Disponível em www.census.gov/population consultado em 05/08/2003.

VENDRUSCOLO Rosecler, LOVISOLO Hugo, Representações de pessoas idosas sobre as atividades corporais, Motus Corporis, v. 4, n. 2, nov, p: 14-48, 1997. VIGARELLO GEORGES, O limpo e o sujo, São Paulo: Martins Fontes, 1996.

\author{
Recebido em 07/05/2004 \\ Aprovado em 18/06/2004 \\ Edmundo de Drummond Alves Junior \\ Rua Assunção 162/ 203 \\ Botafogo \\ Rio de Janeiro RJ \\ 22251030 \\ drummond@bighost.com.br
}

Movimento, Porto Alegre, v. 10, n. 2, p.57-71, maio/agosto de 2004 